\title{
Hospital volume-outcome relationship in total knee arthroplasty: a systematic review and dose-response meta-analysis
}

\author{
C. M. Kugler ${ }^{1}$ (D) $\cdot$ K. Goossen ${ }^{1} \cdot$ T. Rombey Rom $^{1,2} \cdot$ K. K. De Santis ${ }^{1,3} \cdot$ T. Mathes $^{1} \cdot$ J. Breuing $^{1} \cdot$ S. Hess $^{1} \cdot$ R. Burchard $^{4,5,6}$. \\ D. Pieper ${ }^{1}$
}

Received: 21 April 2021 / Accepted: 6 August 2021 / Published online: 8 September 2021

(c) The Author(s) 2021

\begin{abstract}
Purpose This systematic review and dose-response meta-analysis aimed to investigate the relationship between hospital volume and outcomes for total knee arthroplasty (TKA).

Methods MEDLINE, Embase, CENTRAL and CINAHL were searched up to February 2020 for randomised controlled trials and cohort studies that reported TKA performed in hospitals with at least two different volumes and any associated patientrelevant outcomes. The adjusted effect estimates (odds ratios, OR) were pooled using a random-effects, linear dose-response meta-analysis. Heterogeneity was quantified using the $I^{2}$-statistic. ROBINS-I and the GRADE approach were used to assess the risk of bias and the confidence in the cumulative evidence, respectively.

Results A total of 68 cohort studies with data from 1985 to 2018 were included. The risk of bias for all outcomes ranged from moderate to critical. Higher hospital volume may be associated with a lower rate of early revision $\leq 12$ months (narrative synthesis of $k=7$ studies, $n=301,378$ patients) and is likely associated with lower mortality $\leq 3$ months $(\mathrm{OR}=0.91$ per additional 50 TKAs/year, 95\% confidence interval [0.87-0.95], $k=9, n=2,638,996, I^{2}=51 \%$ ) and readmissions $\leq 3$ months $\left(\mathrm{OR}=0.98\right.$ [0.97-0.99], $\left.k=3, n=830,381, I^{2}=44 \%\right)$. Hospital volume may not be associated with the rates of deep infections within 1-4 years, late revision (1-10 years) or adverse events $\leq 3$ months. The confidence in the cumulative evidence was moderate for mortality and readmission rates; low for early revision rates; and very low for deep infection, late revision and adverse event rates.

Conclusion An inverse volume-outcome relationship probably exists for some TKA outcomes, including mortality and readmissions, and may exist for early revisions. Small reductions in unfavourable outcomes may be clinically relevant at the population level, supporting centralisation of TKA to high-volume hospitals.

Level of evidence III.

Registration number The study was registered in the International Prospective Register of Systematic Reviews (PROSPERO CRD42019131209 available at: https://www.crd.york.ac.uk/prospero/display_record.php?RecordID=131209).
\end{abstract}

Keywords Total knee arthroplasty (TKA) - Knee osteoarthritis $\cdot$ Hospital volume $\cdot$ Hospital volume-outcome relationship · Systematic review $\cdot$ Dose-response meta-analysis

C. M. Kugler

charlotte.kugler@uni-wh.de

1 Institute for Research in Operative Medicine (IFOM), Witten/Herdecke University, Ostmerheimer Str. 200, 51109 Cologne, Germany

2 Department of Health Care Management, Technische Universität Berlin, Straße des 17. Juni 135, 10623 Berlin, Germany

3 Leibniz Institute for Prevention Research and Epidemiology (BIPS), Achterstr. 30, 28359 Bremen, Germany
4 Department of Orthopaedics and Trauma Surgery, Lahn-Dill-Kliniken, Rotebergstr. 2, 35683 Dillenburg, Germany

5 Department of Health, Witten/Herdecke University, Alfred-Herrhausen-Straße 50, 58448 Witten, Germany

6 Department of Orthopaedics and Traumatology, University of Giessen and Marburg, Baldingerstraße, 35032 Marburg, Germany 


\begin{tabular}{|c|c|}
\hline \multicolumn{2}{|c|}{ Abbreviations } \\
\hline $\mathrm{CI}$ & Confidence interval \\
\hline GRADE & $\begin{array}{l}\text { Grading of recommendations, assessment, } \\
\text { development, and evaluation }\end{array}$ \\
\hline$k$ & Number of studies \\
\hline$n$ & Patients with event (outcome) \\
\hline$N$ & Number of patients at risk \\
\hline OR & Odds ratio \\
\hline PRESS & Peer review of electronic search strategies \\
\hline PRISMA & $\begin{array}{l}\text { Preferred reporting items for systematic } \\
\text { reviews and meta-analyses }\end{array}$ \\
\hline ROBINS-I & $\begin{array}{l}\text { Risk of bias in non-randomised studies of } \\
\text { interventions }\end{array}$ \\
\hline SWiM & Synthesis Without Meta-analysis \\
\hline TKA & Total knee arthroplasty \\
\hline
\end{tabular}

\section{Introduction}

Total knee arthroplasty (TKA) can improve pain and function in patients with end-stage knee osteoarthritis [99] and is increasingly performed worldwide [48, 87]. Unfavourable outcomes of TKA include revision surgery, deep infection, readmissions, and mortality, though rates of mortality are low $[12,24,87]$.

A hospital volume-outcome relationship exists for various surgical procedures, meaning that higher hospital volume is associated with improved health outcomes [59, 84]. Some countries have therefore centralised selected surgical procedures to high-volume hospitals $[70,86]$. A volume-outcome relationship may also exist for TKA [36, 84, 106]. Previous systematic reviews [26, 62, 107] are likely out of date, and have methodical limitations. The only published meta-analysis compared TKA outcomes only between the highest and lowest hospital volume categories [107].

The aim of this systematic review was to quantify the relationship between hospital volume and patient-relevant outcomes of TKA including complications using a dose-response meta-analysis. The hypothesis was that, as with other surgical procedures, a higher hospital volume would be associated with better patient-relevant outcomes of TKA.

\section{Methods}

The reporting of this systematic review adheres to the Preferred Reporting Items for Systematic Reviews and MetaAnalyses (PRISMA) 2020 Statement [80]. The protocol was registered prospectively in the Prospective Register of Systematic Reviews (PROSPERO registration number CRD42019131209 [89] and published upfront [90].

\section{Systematic literature search}

The search strategies were developed with the support of an experienced librarian according to the Peer Review of Electronic Search Strategies (PRESS) guideline [63]. The electronic search was conducted without any limits in four databases (MEDLINE, Embase, CENTRAL, CINAHL; Supplementary Material 1) from inception to February 2020 and in trial registers (ClinicalTrials.gov, German Clinical Study Register, International Clinical Trials Registry Platform). Further sources of literature included conference proceedings, reference lists of included studies, forward citation searching (Web of Science) and contact with experts (Supplementary Table 1). No language restriction was applied. Articles published in languages other than English, German, or Italian were sent for professional translation.

\section{Study selection}

Studies with any design that (1) involved patients undergoing primary and/or revision TKA, (2) reported data for at least two different hospital volumes, and (3) analysed at least one patient-relevant outcome were included (see Supplementary Table 2 for a full list of eligibility criteria). After the duplicates were removed, two reviewers independently screened the titles and abstracts of all retrieved sources in EndNote (Clarivate Analytics, version X9.1) and assessed the full text of all potentially eligible articles. Any discrepancies were resolved by consensus or, when necessary, by consultation with a third reviewer.

\section{Data extraction}

Data were extracted independently by two reviewers using standardised data extraction sheets. Any discrepancies were resolved by consensus. The data items included study, patient, hospital and surgeon characteristics; time and country of data collection; data source; hospital volume definitions; TKA details; patient-relevant outcomes; and statistical analysis details (effect size types, confidence intervals, and confounding factors). The primary outcome was the early revision rate $\leq 12$ months after TKA. The secondary outcomes were any other patient-relevant outcomes that were classified according to clinical experience as 'main outcomes' [41] or 'other outcomes'. All extracted outcomes are summarised and defined in Supplementary Table 3. Study results (adjusted and/or unadjusted) were extracted separately for each hospital volume category and outcome. If data were missing or incompletely reported, study authors were contacted via email [37]. 


\section{Risk of bias and publication bias}

The risk of bias in the included studies was independently assessed at the outcome level by two reviewers using the Risk Of Bias In Non-randomised Studies of Interventions (ROBINS-I) tool [108]. For any outcomes with at least ten studies, assessment of publication bias was planned by visual inspection of the funnel plots for asymmetry and by applying Egger's [31] and Begg's tests [10].

\section{Statistical analysis}

Hospital volume was defined as the mean annual number of patients undergoing TKA. Hospital volume categories were standardised using their midpoints. For individual study outcomes, odds ratios (ORs) with $95 \%$ confidence intervals (95\% CIs) were converted such that the lowest volume category was the reference.

Individual study results were plotted to visually inspect linearity (e.g. better outcomes with increasing volume) for each outcome. A random-effects linear dose-response meta-analysis according to Greenland and Longnecker [38] was used to pool ORs for outcomes reported in at least three studies with sufficient data (Supplementary Material 2). For each outcome, measurements $\leq 3$ months after TKA were aggregated in one analysis and those $>3$ months in another. Revisions were aggregated in three analyses: $\leq 12$ months, $1-5$ years, and 6-10 years after TKA. Wherever the overlap among two or more study samples exceeded $20 \%$, only one study was selected for meta-analysis based on data completeness, sample size, and the suitability of the volume categories as criteria (Supplementary Tables 4, 5, 6). The main dose-response meta-analysis was computed using the 'best-adjusted' effect estimates. These were the ORs adjusted for at least one confounding variable, including age, gender, and comorbidities, but not for post- or within-intervention variables such as surgeon volume. Heterogeneity between studies was assessed using the $Q$ test and $I^{2}$-statistic [46]. Four sensitivity analyses (Supplementary Material 3) were conducted; the first analysis compared extreme volume categories (highest vs. lowest), and the second, third and fourth analyses (post hoc) studied the influence of confounding variables. An additional post hoc dose-response meta-analysis was conducted using 'best available' (adjusted and unadjusted) effect estimates. All meta-analyses were performed with R 3.6.3 (R Foundation for Statistical Computing, Vienna, Austria) using the metafor and dosresmeta packages [25, 116]. Outcomes that were not suitable for meta-analysis (Supplementary Material 2) were synthesised narratively using the Synthesis Without Meta-analysis (SWiM) guideline (Supplementary Material 4) [20].

\section{Grading the evidence}

Confidence in the cumulative evidence was evaluated using the Grading of Recommendations, Assessment, Development, and Evaluation (GRADE) approach [19, 41, 91, 95, 113] and applying Murad's approach [72] for SWiM outcomes. Two reviewers independently graded outcomes using GRADEpro GDT software [64] and reached consensus during discussion.

\section{Patient involvement}

Potential TKA patients were asked for their opinions on the hospital volume-outcome relationship for TKA and their hospital preferences using qualitative methodology (focus groups and interviews). The methods and results are reported elsewhere [55].

\section{Results}

\section{Study identification and selection}

A total of 13,048 records were identified from electronic databases and trial registers, and 2266 were identified from reference lists of included articles, forward citation search, websites, and author contact. Of 347 full-text reports, 269 were excluded (Supplementary Table 7). This review included 68 cohort studies reported in 78 articles [1-9, 13, $16-18,21-24,27-30,32-35,39,40,42-45,47,49-54$, $57,58,60,61,65,67,68,71,73-79,81-83,85,88,92-94$, $97,98,100-104,110-112,114,115,118-122]$ with data representing the years from 1985 to 2018 (Fig. 1).

\section{Study and patient characteristics}

The majority of studies used data from North America, while 22 used data from Europe, 9 from Asia and 1 from Australia. The data were obtained from administrative databases in 47 studies, clinical registries in 18 studies, and questionnaires in three studies. The average number of patients across all studies was 222,038 (data from 65 studies), with a median of $65 \%$ females (IQR $62-69 \%$, data from 56 studies). The patients had a weighted mean age of 71 years (data from 40 studies). Each study included a median of 486 hospitals (IQR: 43-569, data from 51 studies). In 55 studies, the population was limited to primary TKA patients, 12 included primary and revision TKA patients, and one study did not specify the type of TKA. The study and patient characteristics of studies reporting primary and main secondary outcomes are shown in 


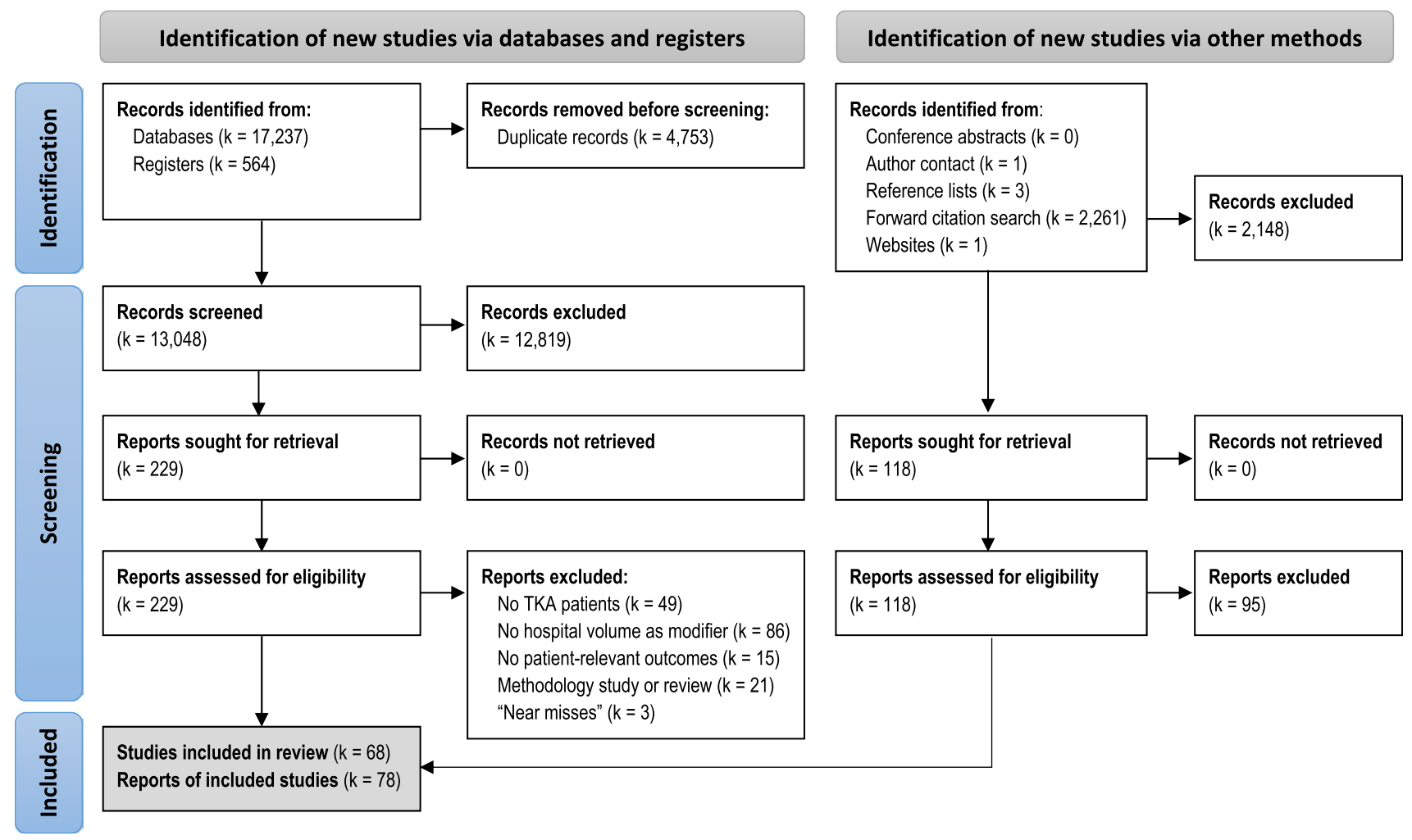

Fig. 1 PRISMA flow diagram showing selection of articles for review

Table 1, and the characteristics of all 68 included studies are shown in Supplementary Table 8.

\section{Study results}

Individual study results are reported for all adjusted or unadjusted outcomes by hospital volume category in Supplementary Tables 4 and 9, respectively, and are summarised for the primary outcome (early revision rates) in Table 2.

\section{Risk of bias}

The risk of bias was moderate for 30 study outcomes, serious for 168 , and critical for 3 (Supplementary Table 10). Bias was suspected mostly due to potential confounding, since most effect estimates were not appropriately adjusted for age, gender, and comorbidity.

\section{Primary outcome: early revision rate}

A higher hospital volume may be associated with a lower early revision rate (7 studies [5, 50, 54, 61, 65, 82, 83], narrative synthesis Table 2, low certainty evidence). Five studies with a high risk of bias, which accounted for 261,243 of $301,378(87 \%)$ patients in total for this outcome
[50, 54, 61, 65, 83], reported lower revision rates for higher volumes. In contrast, the only study with a moderate risk of bias [5] found that a higher hospital volume (>125 TKAs/ year) was associated with a higher early revision rate.

\section{Main secondary outcomes}

The results of the linear dose-response meta-analysis of best-adjusted effect estimates are presented in Table 3 (main secondary outcomes), Supplementary Table 11 (other secondary outcomes) and Supplementary Table 12 (post hoc linear dose-response meta-analysis using 'best available' effect estimates).

\section{Revision}

There was no evidence for a linear dose-response relationship between hospital volume and revision rate within $1-5$ years $(\mathrm{OR}=0.96$ per $50 \mathrm{TKAs} /$ year increase, $95 \% \mathrm{CI}$ [0.86-1.07]; 5 studies [5, 50, 51, 54, 73], $I^{2}=98 \%$, very low certainty, Table 3$)$. This finding was robust to sensitivity analyses (Supplementary Tables 13, 14, 16). 


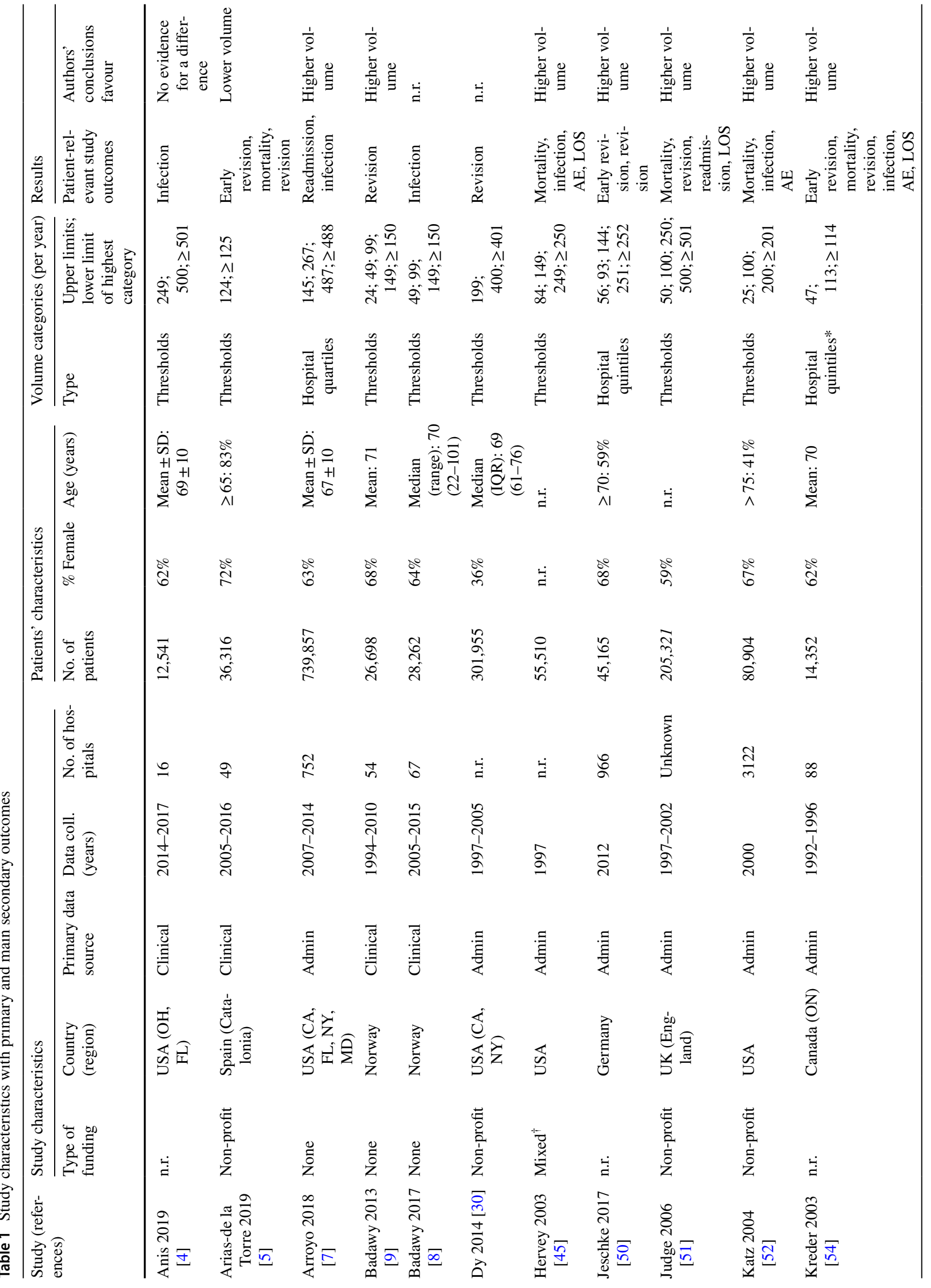




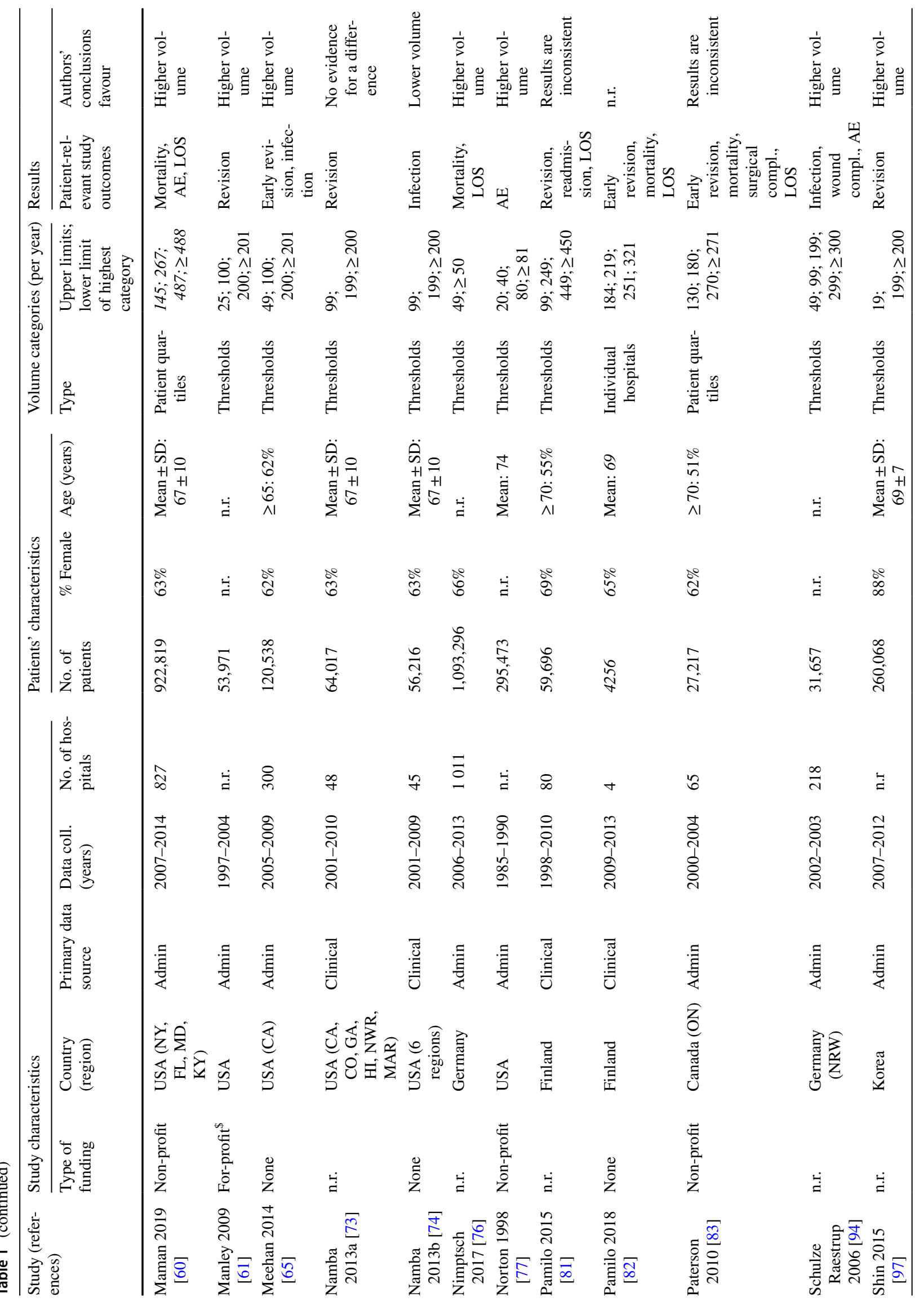




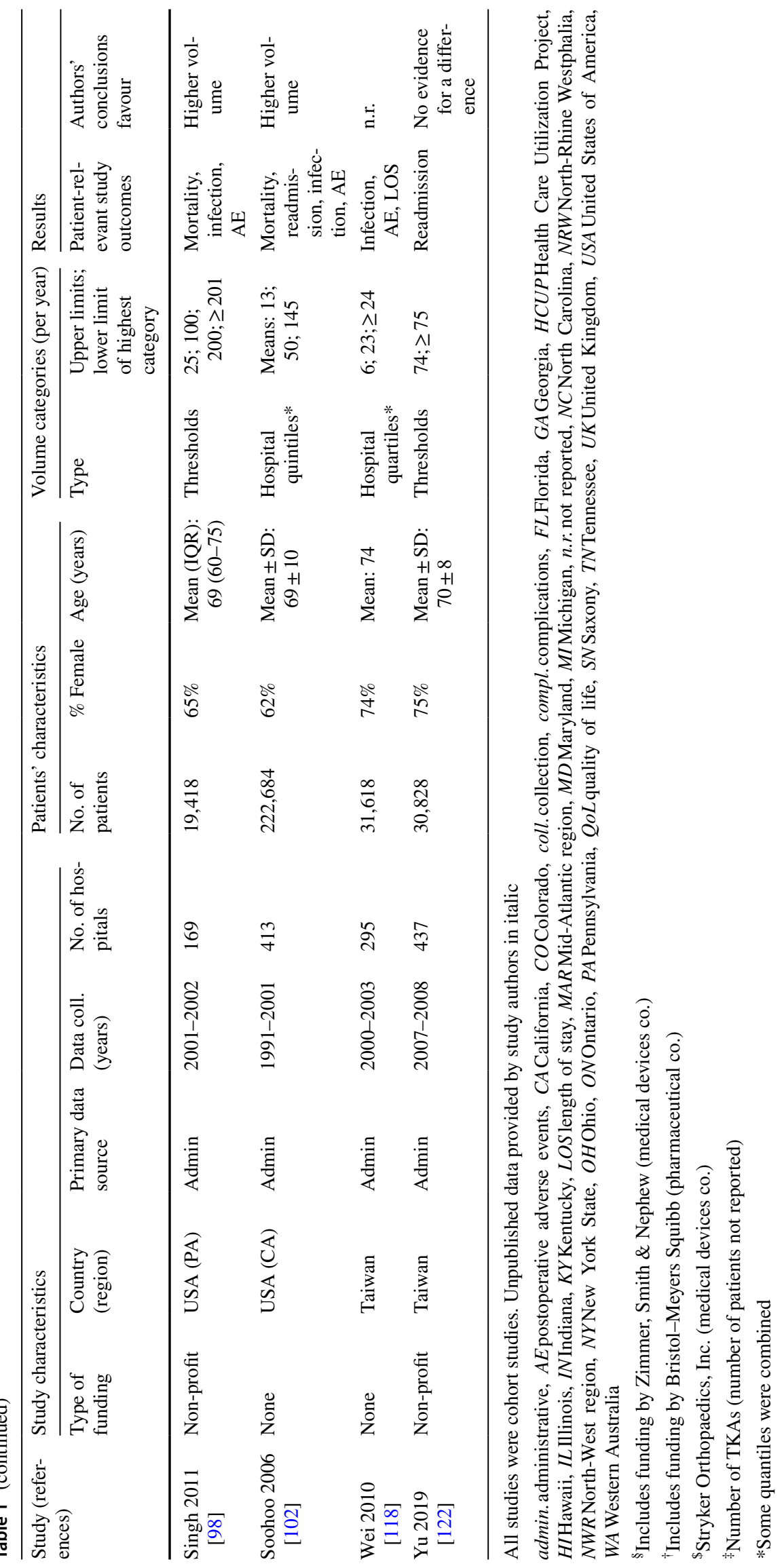


Table 2 Study results and risk of bias for early revision

\begin{tabular}{|c|c|c|c|c|c|c|}
\hline \multirow[t]{2}{*}{ Study (references) } & \multicolumn{3}{|c|}{ Study characteristics } & \multicolumn{2}{|l|}{ Results } & \multirow{2}{*}{$\begin{array}{l}\text { Risk of bias } \\
\text { (ROBINS-I) }\end{array}$} \\
\hline & Country & Time period (years) & No. of patients & Volume categories (TKA/year) & Effect measure & \\
\hline Meehan 2014 [65] & USA & $2005-2009$ & 120,538 & $\begin{array}{l}1-49 \\
50-100 \\
101-200 \\
>200\end{array}$ & $\begin{array}{l}\text { Crude rate } \\
2.52 \% \\
2.32 \% \\
1.96 \% \\
1.78 \%\end{array}$ & Serious \\
\hline Pamilo 2018 [82] & Finland & 1998-2010 & 59,696 & \multicolumn{2}{|c|}{$\begin{array}{l}\text { No differences in revision rates between hospital } \\
\text { volume with data from only four hospitals with } \\
\text { similar TKA volumes }\end{array}$} & Serious \\
\hline Manley 2009 [61] & USA & 1997-2004 & 53,971 & $\begin{array}{l}1-25 \\
26-100 \\
101-200 \\
>200\end{array}$ & $\begin{array}{l}\text { Adjusted OR [CI] } \\
1.91[0.76-4.83] \\
1.38[0.84-2.26] \\
1.17[0.74-1.87] \\
1.00\end{array}$ & Serious \\
\hline Jeschke 2017 [50] & Germany & 2012 & 45,165 & $\begin{array}{l}10-56 \\
57-93 \\
94-144 \\
145-251 \\
252-1648\end{array}$ & $\begin{array}{l}\text { Crude rate } \\
5.19 \% \\
4.26 \% \\
3.81 \% \\
3.49 \% \\
3.34 \%\end{array}$ & Serious \\
\hline Arias-de la Torre 2019 [5] & Spain & 2005-2016 & 36,316 & $\begin{array}{l}<125 \\
\geq 125\end{array}$ & $\begin{array}{l}\text { Crude rate; } \\
\text { Kaplan-Meier } \\
\text { rate }[\mathrm{CI}] \\
0.67 \% ; 0.64 \% \\
{[0.53-0.77 \%]} \\
1.24 \% ; 1.15 \% \\
{[1.00-1.32 \%]}\end{array}$ & Moderate \\
\hline Paterson 2010 [83] & Canada & 2000-2004 & 27,217 & $\begin{array}{l}10-130 \\
131-180 \\
181-270 \\
>270\end{array}$ & $\begin{array}{l}\text { Adjusted OR [CI] } \\
1.00 \\
0.64[0.39-1.04] \\
0.62[0.42-0.91] \\
0.50[0.34-0.72]\end{array}$ & Serious \\
\hline Kreder 2003 [54] & Canada & 1992-1996 & 14,352 & $\begin{array}{l}<48 \\
48-113 \\
>113\end{array}$ & $\begin{array}{l}\text { Adjusted OR [CI] } \\
2.23[1.10-4.50] \\
1.57[0.90-2.90] \\
1.00\end{array}$ & Serious \\
\hline
\end{tabular}

CI confidence interval, OR odds ratio, ROBINS-I risk of bias in non-randomised studies of interventions tool, TKA total knee arthroplasty

Table 3 Results of linear dose-response meta-analysis of best-adjusted effect estimates (main secondary outcomes)

\begin{tabular}{|c|c|c|c|c|c|c|}
\hline Outcome & $k$ & $(n / N)[\%]$ & $I^{2}$ & $\begin{array}{l}\text { Pooled } O R[95 \% \mathrm{CI}] \text { for } 50 \\
\text { TKA/year increase }\end{array}$ & $\begin{array}{l}\text { Risk of bias } \\
\text { (ROBINS-I) }\end{array}$ & References \\
\hline Mortality ( $\leq 3$ months) & 9 & $4769 / 2,638,996(0.2 \%)$ & $51 \%$ & $\mathbf{0 . 9 1}[0.87-0.95]$ & Moderate $^{\mathrm{a}}$ & $\begin{array}{l}{[45,51,52,54} \\
60,76,83,98 \\
104]\end{array}$ \\
\hline Infection (deep) (1-4 years) & 3 & $797 / 97,019(0.8 \%)$ & $0 \%$ & $1.03[0.97-1.09]$ & Serious ${ }^{b}$ & {$[4,8,74]$} \\
\hline Revision ( $1-5$ years) & 5 & $5498 / 163,520(3.4 \%)$ & $98 \%$ & $0.96[0.86-1.07]$ & Serious $^{\mathrm{c}}$ & {$[5,50,51,54,73]$} \\
\hline Readmission ( $\leq 3$ months) & 3 & $78,895 / 830,381(9.5 \%)$ & $44 \%$ & $\mathbf{0 . 9 8}[0.97-0.99]$ & Serious $^{c}$ & {$[7,81,122]$} \\
\hline
\end{tabular}

Statistically significant results in bold

$C I$ confidence interval, $I^{2}$ index for residual heterogeneity, $k$ number of studies, $n$ patients with event, $N$ number of patients at risk, $O R$ odds ratio, ROBINS-I risk of bias in non-randomised studies of interventions tool, TKA total knee arthroplasty

${ }^{a}$ Overall risk of bias was serious in five studies and moderate in four studies. Since studies with moderate risk of bias dominated the results (accounted for more than $80 \%$ of patients and events), we assume that the overall result is not seriously biased

${ }^{\mathrm{b}}$ Overall risk of bias was serious in all studies

${ }^{\mathrm{c}}$ Overall risk of bias was serious in all but one study, and moderate in one study 
The relationship between hospital volume and revision rate within 6-10 years was inconsistent (narrative synthesis, 5 studies [5, 9, 30, 81, 97], very low certainty).

\section{Mortality}

A higher hospital volume is likely associated with a lower mortality rate $\leq 3$ months $(\mathrm{OR}=0.91$ per additional 50 TKAs/year, 95\% CI [0.87-0.95]; 9 studies [45, 51, 52, 54, $60,76,83,98,104], I^{2}=51 \%$, moderate certainty, Table 3 , Fig. 2a). The direction of this relationship was robust to sensitivity analyses (Supplementary Tables 13-16), although the pooled OR was no longer significant when the analysis included only data that were also adjusted for surgeon volume (Supplementary Table 15).

\section{Deep infection}

There was no evidence for a linear dose-response association between hospital volume and the rate of deep infection within $1-4$ years $(\mathrm{OR}=1.03$ per 50 additional TKAs/ year, 95\% CI [0.97-1.09], 3 studies [ $4,8,74], I^{2}=0 \%$, very low certainty, Table 3 ). However, the sensitivity analysis comparing highest vs. lowest volume categories showed that higher hospital volume may be associated with a higher rate of deep infection $\left(\mathrm{OR}=1.60 ; 95 \% \mathrm{CI}[0.91-2.82], I^{2}=54 \%\right.$, Supplementary Table 13).

\section{Adverse events}

Due to the heterogeneous clinical definitions of adverse events in the primary studies (Supplementary Table 3), this outcome was not pooled. The relationship between hospital volume and adverse event rates $\leq 3$ months was inconsistent across studies in a narrative synthesis (Supplementary Tables 4,9$)$, and the certainty was very low based on 7 studies $[52,54,60,77,94,98,118]$.

\section{Readmission}

A higher hospital volume was likely associated with a slightly lower readmission rate $\leq 3$ months $(\mathrm{OR}=0.98 ; 95 \%$ CI [0.97-0.99], 3 studies [7, 81, 122], $I^{2}=44 \%$, moderate certainty, Table 3, Fig. 2b). The direction of this relationship was robust to sensitivity analyses (Supplementary Tables 13, 14), although the relationship was no longer statistically significant when only unadjusted effect estimates were included (Supplementary Table 16).

\section{Other secondary outcomes}

Limited evidence (Supplementary Table 6) showed that higher hospital volume may be associated with lower rates of the following outcomes:

1. Composite adverse events including mortality $\leq 3$ months [22, 40, 57, 98, 104],

2. Any infection $\leq 3$ months $[45,98,104,118]$ and $>3$ months $[22,54,104]$

3. Length of hospital stay $[1,32,33,45,47,51,54,60,68$, $76,81,83,85,110,111,118,121]$,

4. Pneumonia $\leq 3$ months [52],

5. Superficial infection $\leq 3$ months $[7,49,78]$ and $>3$ months $[3,71,101]$,

6. 'Surgical complications' as a composite outcome $\leq 3$ months [18, 40, 47, 83, 94],

7. Thromboembolic events $\leq 3$ months $[45,52,98,104]$ and $>3$ months [104] and,
Fig. 2 Linear dose-response meta-analysis for mortality (a) and readmission (b)
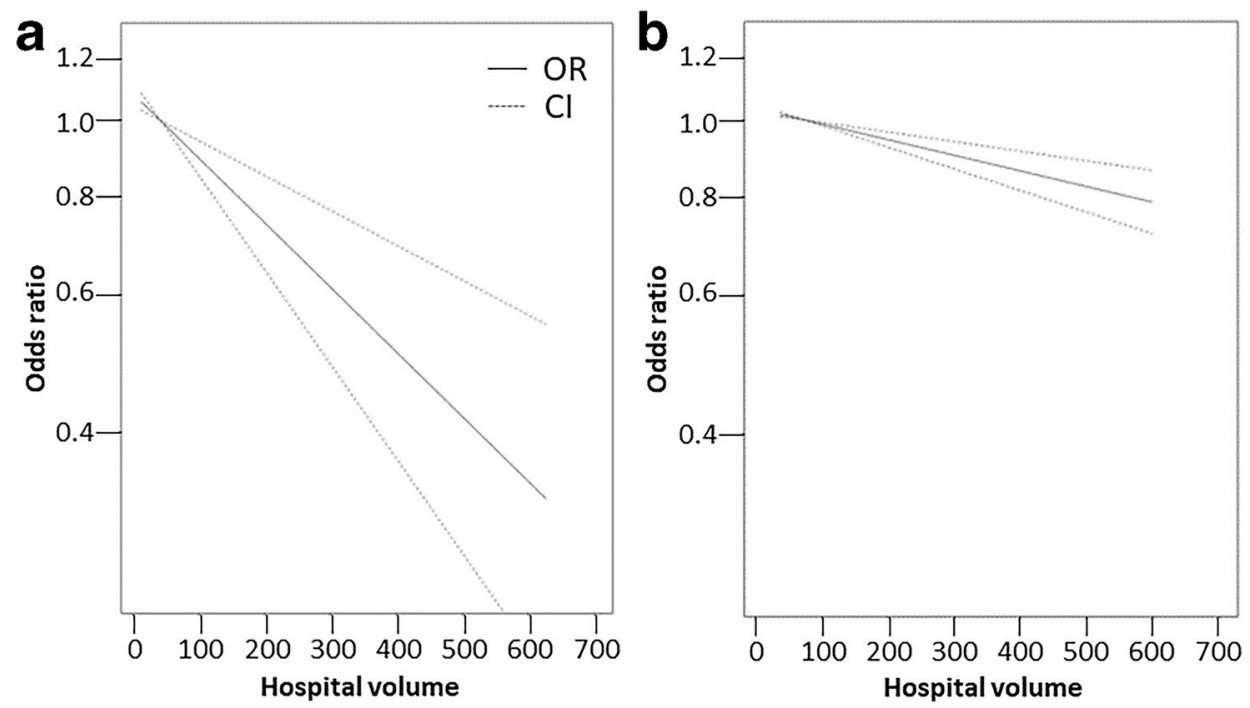
8. Thrombophlebitis $\leq 3$ months [104] and $>3$ months [104].

Hospital volume may be associated with function $\leq 3$ months in a U-shaped relationship [42, 49]. Specifically, postoperative mobility at discharge appeared to be highest at hospital volumes of approximately $300-400$
TKAs/year, and hospitals with lower or higher TKA volumes had worse outcomes [49].

There was no evidence for a relationship between hospital volume and the rates of the following outcomes:

1. Deep infection $\leq 3$ months $[52,58]$,

2. Mortality $>3$ months [22, 40, 57, 98, 104],

3. Myocardial infarction $\leq 3$ months $[17,52,98]$,

Table 4 Summary of findings and certainty of evidence (GRADE)

\begin{tabular}{|c|c|c|c|c|c|}
\hline \multirow[t]{2}{*}{ Number of studies } & \multirow{2}{*}{$\begin{array}{l}\text { Study event rates } \\
(n / N)[\%]\end{array}$} & \multicolumn{2}{|l|}{ Effect } & \multirow{2}{*}{$\begin{array}{l}\text { Certainty } \\
\text { Certainty rating } \\
\text { Reason for rating }\end{array}$} & \multirow[t]{2}{*}{ Importance } \\
\hline & & $\begin{array}{l}\text { Extreme comparison } \\
\text { Relative }[95 \% \mathrm{CI}] \\
\text { Absolute }[95 \% \mathrm{CI}] \\
\text { Alternatively: SWiM }\end{array}$ & $\begin{array}{l}\text { Dose-response } O R \text { per } \\
50 \mathrm{TKAs} / \text { year increase } \\
{[95 \% \mathrm{CI}]}\end{array}$ & & \\
\hline \multicolumn{6}{|c|}{ Primary outcome: early revision ( $\leq 12$ months) } \\
\hline $\begin{array}{l}7 \text { studies in SWiM [5, } \\
50,54,61,65,82,83]\end{array}$ & $N=301,378$ & \multicolumn{2}{|c|}{$\begin{array}{l}\text { In } 5 \text { studies accounting for } 87 \% \text { of patients, higher } \\
\text { hospital volume was associated with lower rates of } \\
\text { early revision }\end{array}$} & $\begin{array}{l}\oplus \oplus \bigcirc \\
\text { Low } \\
-2 \text { for risk of bias }\end{array}$ & Critical \\
\hline \multicolumn{6}{|l|}{ Main secondary outcomes } \\
\hline \multicolumn{6}{|c|}{ Mortality (all cause, $\leq 3$ months) } \\
\hline $\begin{array}{l}9 \text { studies in meta- } \\
\text { analysis }[45,51,52 \\
54,60,76,83,98 \\
104]\end{array}$ & $4769 / 2,638,996(0.2 \%)$ & $\begin{array}{l}\text { OR } \mathbf{0 . 6 2} \\
{[0.48-0.79]} \\
\mathbf{1} \text { fewer per } \mathbf{1 0 0 0} \\
\text { (from } 1 \text { to } 0 \text { fewer) }\end{array}$ & $\begin{array}{l}\text { Linear dose-response } \\
\text { gradient } \\
\text { OR } 0.91[\mathbf{0 . 8 7 - 0 . 9 5}]\end{array}$ & $\begin{array}{l}\oplus \oplus \oplus \bigcirc \\
\text { Moderate } \\
-1 \text { for risk of bias } \\
-1 \text { for inconsistency } \\
+1 \text { for dose-response } \\
\text { gradient }\end{array}$ & Critical \\
\hline \multicolumn{6}{|c|}{ Infection (deep) ( $1-4$ years) } \\
\hline $\begin{array}{l}3 \text { studies in meta- } \\
\text { analysis }[4,8,74]\end{array}$ & 797/97,019 (0.8\%) & $\begin{array}{l}\text { OR 1.60 } \\
{[0.91-2.82]} \\
\mathbf{5} \text { more per } \mathbf{1 0 0 0} \\
\text { [from } 1 \text { fewer to } 15 \\
\quad \text { more] }\end{array}$ & $\begin{array}{l}\text { No evidence for a dose- } \\
\text { response association }\end{array}$ & $\begin{array}{l}\oplus \bigcirc \bigcirc \bigcirc \\
\text { Very low } \\
-2 \text { for risk of bias, } \\
-1 \text { for imprecision }\end{array}$ & Critical \\
\hline \multicolumn{6}{|l|}{ Revision (1-5 years) } \\
\hline $\begin{array}{l}5 \text { studies in meta- } \\
\text { analysis }[5,50,51 \text {, } \\
54,73]\end{array}$ & $5,498 / 163,520(3.4 \%)$ & $\begin{array}{l}\text { OR } 0.99 \\
{[0.65-1.50]} \\
\text { 0 fewer per } 1000 \\
\text { [from } 12 \text { fewer to } 16 \\
\text { more] }\end{array}$ & $\begin{array}{l}\text { No evidence for a dose- } \\
\text { response association }\end{array}$ & $\begin{array}{l}\oplus \circ \circ \bigcirc \\
\text { Very low } \\
-2 \text { for risk of bias, } \\
-1 \text { for inconsistency, } \\
-1 \text { for imprecision }\end{array}$ & Important \\
\hline \multicolumn{6}{|c|}{ Adverse events ( $\leq 3$ months) } \\
\hline $\begin{array}{l}7 \text { studies in SWiM } \\
{[52,54,60,77,94} \\
98,118]\end{array}$ & $N=1,396,241$ & \multicolumn{2}{|c|}{$\begin{array}{l}\text { The effect of hospital volume on this composite } \\
\text { outcome was inconsistent across studies }\end{array}$} & $\begin{array}{l}\oplus \circ \bigcirc \bigcirc \\
\text { Very low } \\
-2 \text { for risk of bias, } \\
-1 \text { for inconsistency }\end{array}$ & Important \\
\hline \multicolumn{6}{|l|}{ Revision (6-10 years) } \\
\hline $\begin{array}{l}5 \text { studies in SWiM [5, } \\
9,30,81,97]\end{array}$ & $N=684,733$ & \multicolumn{2}{|c|}{ Results were inconsistent across studies } & $\begin{array}{l}\oplus \bigcirc \bigcirc \bigcirc \\
\text { Very low } \\
-2 \text { for risk of bias, } \\
-1 \text { for inconsistency }\end{array}$ & Important \\
\hline \multicolumn{6}{|l|}{ Readmission ( $\leq 3$ months) } \\
\hline $\begin{array}{l}3 \text { studies in meta- } \\
\text { analysis }[7,81,122]\end{array}$ & $78,895 / 830,381(9.5 \%)$ & $\begin{array}{l}\text { OR } 0.85 \\
{[0.74-0.98]} \\
\mathbf{1 3} \text { fewer per } 1000 \\
\text { [from } 23 \text { to } 2 \text { fewer] }\end{array}$ & $\begin{array}{l}\text { Linear dose-response } \\
\text { gradient, } \\
\text { OR } 0.98 \text { [0.97-0.99] }\end{array}$ & $\begin{array}{l}\oplus \oplus \oplus \bigcirc \\
\text { Moderate } \\
-2 \text { for risk of bias } \\
+1 \text { for dose-response } \\
\text { gradient }\end{array}$ & Important \\
\hline
\end{tabular}

$C I$ confidence interval, $I^{2}$ index for residual heterogeneity, $k$ number of studies, $n$ patients with event, $N$ number of patients at risk, $O R$ odds ratio, ROBINS-I risk of bias in non-randomised studies of interventions tool, SWiM synthesis without meta-analysis, TKA total knee arthroplasty 
4. Quality of life $>3$ months [115],

5. Readmission $>3$ months [51] and

6. Wound haematoma or secondary haemorrhage $\leq 3$ months [78].

Although patient satisfaction was reported in two studies [32, 92], we did not synthesise the results due to critical risk of bias.

\section{Certainty of evidence}

Table 4 shows the GRADE assessment and summary of findings for the primary and main secondary outcomes. The individual GRADE domains and the certainty of evidence for the other secondary outcomes are shown in Supplementary Tables 5 and 6 , respectively. The certainty of evidence was moderate for 4 outcomes, low for 7 outcomes, very low for 15 outcomes and not assessed for 1 outcome.

\section{Discussion}

The current systematic review reports the results of a dose-response meta-analysis of 68 cohort studies that assessed the relationship between hospital TKA volume and patient-relevant outcomes. As hypothesised, higher hospital TKA volume may be associated with a lower rate of early revisions and is likely associated with small reductions in mortality and readmission $\leq 3$ months after TKA. Earlier systematic reviews by Critchley [26] and Stengel [107] also found small reductions in mortality with increased hospital TKA volume, whereas Marlow [62] found no evidence for this association.

The certainty of evidence of the synthesised results was reduced by the relatively high risk of bias resulting from the observational design of the primary studies, which lies in the nature of the topic. Furthermore, the selection of endpoints for this systematic review was limited to morbidity and mortality, which are more widely recorded than outcomes related to function and quality of life. As a result, the association of hospital volume with improvements in function, quality of life, and pain reduction (the primary goals of TKA) could not be assessed. Mortality may not be the most relevant endpoint to study from a patient perspective, and overall event rates are very low. Nevertheless, the results may be may be clinically relevant at the population level.

Higher hospital volume does not directly result in improved patient outcomes but, rather, acts as a proxy measure for quality $[66,70]$. Three general explanatory factors for the hospital volume-outcome relationship have been identified for various medical procedures: level of specialisation, hospital-level factors including nursing staff and facilities, and compliance with evidence-based processes [66]. In addition, there is a tendency for a surgeon volume-outcome relationship in TKA surgery [69]. Based on the results of this systematic review, surgeon volume could constitute one aspect of the hospital volume-outcome relationship, since the meta-analysis no longer showed a significant association with mortality when only data adjusted for surgeon volume were included (Supplementary Table 15). In several types of cancer surgeries and cardiovascular procedures, surgeon volume accounts for a large proportion of the effect of hospital volume [15]. Therefore, the authors interpret hospital volume as a proxy for quality, of which surgeon volume is one element. Additional confounders exist, e.g. patient characteristics [26] and changing suppliers of implant systems [105].

Understanding the volume-outcome relationship is important in light of discussions regarding the centralisation of surgical procedures to specialised hospitals [14, 62]. These results suggest that centralising TKA surgery may improve patient outcomes. A drawback of centralisation is that it may increase patients' travel burden and reduce access for disadvantaged patients $[14,56,66,96]$.

Future studies should adhere to reporting guidelines $[11,117]$ so that their data can be used more effectively for further research. To evaluate whether the volume-outcome relationship for TKA is non-linear, a future primary study could use multinational registry data. Measurement of patient-reported outcomes in the context of the hospital volume-outcome relationship is desirable.

This systematic review has several limitations. First, the results are based on a relatively small number of studies for most outcomes, although a large number of studies were included in this systematic review. This was because primary studies did not report the same outcomes, and time points or data required for the dose-response meta-analysis were missing. Second, the small number of volume categories in the primary studies may have hidden non-linear relationships, which could therefore have gone undetected by a dose-response meta-analysis. Third, the applicability of the results to other healthcare systems is limited because a large proportion of data were collected in North America. Fourth, there was considerable between-study heterogeneity for most outcomes, probably due to inconsistent methodology in primary studies, variation among healthcare systems and regulatory approaches, and different periods of data collection. Sources of heterogeneity could not be explored by subgroup analysis because there were fewer than three studies per subgroup for each outcome. However, when the highest and lowest volume categories were compared, heterogeneity decreased, and pooled effect estimates showed strengthened associations between hospital volume and outcomes. Fifth, it was not possible to assess publication bias because fewer than ten studies per outcome were included 
in the dose-response meta-analyses [109]. Because of these limitations, conclusions should be drawn from the direction and dimensions of the hospital volume-outcome associations rather than the exact numerical values of the pooled effect sizes.

\section{Conclusion}

Policy makers need solid evidence when regulating surgical procedures. The results for TKA show that there is moderate to low certainty evidence for an inverse hospital volume-outcome relationship for the outcomes of mortality, readmissions and early revisions. These small reductions in unfavourable outcomes may be clinically relevant at the population level. This finding supports the centralisation of TKA surgery to high-volume hospitals.

Supplementary Information The online version contains supplementary material available at https://doi.org/10.1007/s00167-021-06692-8.

Acknowledgements The authors would like to thank Stefanie Bühn for her help in searching study registries.

Author contributions $\mathrm{CMK}$ : data curation, formal analysis, investigation, methodology, validation, visualisation, writing-original draft, and writing - review and editing. KG: conceptualisation, data curation, formal analysis, investigation, methodology, project administration, validation, visualisation, writing - original draft, and writing-review and editing. TR: conceptualisation, data curation, formal analysis, investigation, methodology, project administration, validation, writing — original draft, and writing — review and editing. KKDS: data curation, formal analysis, investigation, methodology, writing-original draft, and writing - review and editing. TM: conceptualisation, formal analysis, investigation, methodology, software, and writingreview and editing. JB: formal analysis, investigation, and writingreview and editing. SH: data curation, investigation, writing —original draft, and writing - review and editing. RB: formal analysis, investigation, and writing - review and editing. DP: conceptualisation, funding acquisition, supervision, and writing—review and editing.

Funding Open Access funding enabled and organized by Projekt DEAL. This project was funded by the German Federal Ministry of Education and Research (BMBF), Grant No. 01KG1805. The funder played no role in the design, conduct, interpretation or dissemination of the study.

Availability of data and material Additional details regarding methodology and data are available upon reasonable request from the corresponding author.

\section{Declarations}

Conflict of interest The authors declare no conflict of interest. No benefits in any form have been received or will be received from a commercial party related directly or indirectly to the subject of this article.

Ethical approval We obtained ethics approval from the ethics committee of Witten/Herdecke University (Reference No. 54/2019) to involve consumers (potentials TKA patients).
Informed consent Informed consents were obtained from all the participants of the qualitative study.

Open Access This article is licensed under a Creative Commons Attribution 4.0 International License, which permits use, sharing, adaptation, distribution and reproduction in any medium or format, as long as you give appropriate credit to the original author(s) and the source, provide a link to the Creative Commons licence, and indicate if changes were made. The images or other third party material in this article are included in the article's Creative Commons licence, unless indicated otherwise in a credit line to the material. If material is not included in the article's Creative Commons licence and your intended use is not permitted by statutory regulation or exceeds the permitted use, you will need to obtain permission directly from the copyright holder. To view a copy of this licence, visit http://creativecommons.org/licenses/by/4.0/.

\section{References}

1. Adhia AH, Feinglass JM, Suleiman LI (2019) What are the risk factors for 48 or more-hour stay and nonhome discharge after total knee arthroplasty? Results from 151 Illinois hospitals, 2016-2018. J Arthroplasty 35(6):1466-1473

2. Amato L, Fusco D, Acampora A, Bontempi K, Rosa AC, Colais $P$ et al (2017) Volume and health outcomes: evidence from systematic reviews and from evaluation of Italian hospital data. Epidemiol Prev 41(5-6 Suppl 2):1-128

3. Anis HK, Mahmood BM, Klika AK, Mont MA, Barsoum WK, Molloy RM et al (2020) Hospital volume and postoperative infections in total knee arthroplasty. J Arthroplast 35(4): 1079-1083

4. Anis HK, Sodhi N, Klika AK, Mont MA, Barsoum WK, Higuera CA et al (2019) Is operative time a predictor for post-operative infection in primary total knee arthroplasty? J Arthroplast 34(7):S331-S336

5. Arias-de la Torre J, Pons-Cabrafiga M, Valderas JM, Evans JP, Martin V, Molina AJ et al (2019) Influence of hospital volume of procedures by year on the risk of revision of total hip and knee arthroplasties: a propensity score-matched cohort study. J Clin Med 8(5):670

6. Arias-de la Torre J, Valderas JM, Evans JP, Martin V, Molina AJ, Munoz L et al (2019) Differences in risk of revision and mortality between total and unicompartmental knee arthroplasty. The influence of hospital volume. J Arthroplast 34(5):865-871

7. Arroyo NS, White RS, Gaber-Baylis LK, La M, Fisher AD, Samaru M (2018) Racial/ethnic and socioeconomic disparities in total knee arthroplasty 30- and 90-day readmissions: a multi-payer and multistate analysis, 2007-2014. Popul Health Manag 22(2):175-185

8. Badawy M, Espehaug B, Fenstad AM, Indrekvam K, Dale H, Havelin LI et al (2017) Patient and surgical factors affecting procedure duration and revision risk due to deep infection in primary total knee arthroplasty. BMC Musculoskelet Disord 18(1):1-9

9. Badawy M, Espehaug B, Indrekvam K, Engesaeter LB, Havelin LI, Furnes O (2013) Influence of hospital volume on revision rate after total knee arthroplasty with cement. J Bone Jt Surg Am 95(18):e131

10. Begg CB, Mazumdar M (1994) Operating characteristics of a rank correlation test for publication bias. Biometrics 50(4):1088-1101

11. Benchimol EI, Smeeth L, Guttmann A, Harron K, Moher D, Petersen I et al (2015) The reporting of studies conducted using 
observational routinely-collected health data (record) statement. PLoS Med 12(10):e1001885

12. Berstock JR, Beswick AD, López-López JA, Whitehouse MR, Blom AW (2018) Mortality after total knee arthroplasty: a systematic review of incidence, temporal trends, and risk factors. J Bone Jt Surg Am 100(12):1064-1070

13. Bini SA, Inacio MCS, Cafri G (2015) Two-day length of stay is not inferior to 3 days in total knee arthroplasty with regards to 30-day readmissions. J Arthroplast 30(5):733-738

14. Birkmeyer JD (2000) Should we regionalize major surgery? Potential benefits and policy considerations. J Am Coll Surg 190(3):341-349

15. Birkmeyer JD, Stukel TA, Siewers AE, Goodney PP, Wennberg DE, Lucas FL (2003) Surgeon volume and operative mortality in the united states. N Engl J Med 349(22):2117-2127

16. Blum MA, Singh JA, Lee GC, Richardson D, Chen W, Ibrahim SA (2013) Patient race and surgical outcomes after total knee arthroplasty: an analysis of a large regional database. Arthritis Care Res (Hoboken) 65(3):414-420

17. Bohm ER, Molodianovitsh K, Dragan A, Zhu N, Webster G, Masri B et al (2016) Outcomes of unilateral and bilateral total knee arthroplasty in 238,373 patients. Acta Orthop 87:24-30

18. Bottle A, Loeffler MD, Aylin P, Ali AM (2018) Comparison of 3 types of readmission rates for measuring hospital and surgeon performance after primary total hip and knee arthroplasty. J Arthroplast 33(7):2014-2019.e2012

19. Brozek JL, Akl EA, Compalati E, Kreis J, Terracciano L, Fiocchi A et al (2011) Grading quality of evidence and strength of recommendations in clinical practice guidelines part 3 of 3 . The grade approach to developing recommendations. Allergy 66(5):588-595

20. Campbell M, McKenzie JE, Sowden A, Katikireddi SV, Brennan SE, Ellis S et al (2020) Synthesis without meta-analysis (swim) in systematic reviews: reporting guideline. BMJ 368:16890

21. Charpentier PM, Srivastava AK, Zheng H, Ostrander JD, Hughes RE (2018) Readmission rates for one versus two-midnight length of stay for primary total knee arthroplasty analysis of the Michigan Arthroplasty Registry collaborative quality initiative (Marcqi) database. J Bone Jt Surg Am 100(20):1757-1764

22. Cheng CH, Cheng YT, Chen JS (2011) A learning curve of total knee arthroplasty (tka) based on surgical volume analysis. Arch Gerontol Geriatr 53(1):e5-9

23. Cram P, Lu X, Kates SL, Li Y, Miller BJ (2011) Outliers: hospitals with consistently lower and higher than predicted joint arthroplasty readmission rates. Geriatr Orthop Surg Rehabil 2(4):135-147

24. Cram P, Lu X, Kates SL, Singh JA, Li Y, Wolf BR (2012) Total knee arthroplasty volume, utilization, and outcomes among Medicare beneficiaries, 1991-2010. JAMA 308(12):1227-1236

25. Crippa A, Orsini N (2016) Multivariate dose-response metaanalysis: the dosresmeta r package. J Stat Softw 72(1):1-15

26. Critchley RJ, Baker PN, Deehan DJ (2012) Does surgical volume affect outcome after primary and revision knee arthroplasty? A systematic review of the literature. Knee 19(5):513-518

27. D’Apuzzo M, Westrich G, Hidaka C, Jung Pan T, Lyman S (2017) All-cause versus complication-specific readmission following total knee arthroplasty. J Bone Jt Surg Am 99(13):1093-1103

28. Dailey L, Van Gessel H, Peterson A (2009) Two years of surgical site infection surveillance in Western Australia: analysing variation between hospitals. Healthc Infect 14(2):51-60

29. Day MS, Karia R, Hutzler L, Bosco JA (2019) Higher hospital costs do not result in lower readmission rates following total joint arthroplasty. Bull Hosp Jt Dis 77(2):136-139
30. Dy CJ, Marx RG, Bozic KJ, Pan TJ, Padgett DE, Lyman S (2014) Risk factors for revision within 10 years of total knee arthroplasty. Clin Orthop Relat Res 472(4):1198-1207

31. Egger M, Davey Smith G, Schneider M, Minder C (1997) Bias in meta-analysis detected by a simple, graphical test. BMJ 315(7109):629-634

32. Featherall J, Brigati DP, Arney AN, Faour M, Bokar DV, Murray TG et al (2019) Effects of a total knee arthroplasty care pathway on cost, quality, and patient experience: toward measuring the triple aim. J Arthroplast 34(11):2561-2568

33. Feinglass J, Amir H, Taylor P, Lurie I, Manheim LM, Chang RW (2004) How safe is primary knee replacement surgery? Perioperative complication rates in northern Illinois, 1993-1999. Arthritis Rheum 51(1):110-116

34. Fry DE, Pine M, Nedza SM, Locke DG, Reband AM, Pine G (2017) Risk-adjusted hospital outcomes in Medicare total joint replacement surgical procedures. J Bone Jt Surg Am 99(1):10-18

35. Geraedts M, Cruppe WD, Blum K, Ohmann C (2008) Implementation and effects of Germany's minimum volume regulations results of the accompanying research. Dtsch Arztebl Int 105(51-52):890-896

36. Geraedts M, Cruppé Wd, Blum K, Ohmann C (2008) Implementation and effects of Germany's minimum volume regulations-results of the accompanying research. Dtsch Arztebl Int 105(51-52):890-896

37. Goossen K, Rombey T, Kugler CM, De Santis KK, Pieper D (2021) Author queries via email text elicited high response and took less reviewer time than data forms - a randomised study within a review. J Clin Epidemiol 135:1-9. https://doi.org/10. 1016/j.jclinepi.2021.02.006

38. Greenland S, Longnecker MP (1992) Methods for trend estimation from summarized dose-response data, with applications to meta-analysis. Am J Epidemiol 135(11):1301-1309

39. Grouven U, Kuchenhoff H, Schrader P, Bender R (2008) Flexible regression models are useful tools to calculate and assess threshold values in the context of minimum provider volumes. $\mathbf{J}$ Clin Epidemiol 61(11):1125-1131

40. Gutierrez B, Culler SD, Freund DA (1998) Does hospital procedure-specific volume affect treatment costs? A national study of knee replacement surgery. Health Serv Res 33(3 Pt 1):489-511

41. Guyatt GH, Oxman AD, Santesso N, Helfand M, Vist G, Kunz R et al (2013) Grade guidelines: 12. Preparing summary of findings tables-binary outcomes. J Clin Epidemiol 66(2):158-172

42. Heck DA, Robinson RL, Partridge CM, Lubitz RM, Freund DA (1998) Patient outcomes after knee replacement. Clin Orthop Relat Res 356:93-110

43. Hentschker C, Mennicken R, Reifferscheid A, Thomas D, Wasem J, Wübker A (2016) Der kausale zusammenhang zwischen zahl der fälle und behandlungsqualität in der krankenhausversorgung (rwi materialien heft 101). Rheinisch-Westfälisches Institut für Wirtschaftsforschung, Essen (Germany). http://www.rwi-essen. de/publikationen/rwi-materialien/377/. Accessed 07 Apr 2020

44. Hentschker C, Mennicken R, Reifferscheid A, Wasem J, Wubker A (2018) Volume-outcome relationship and minimum volume regulations in the german hospital sector-evidence from nationwide administrative hospital data for the years 2005-2007. Health Econ Rev 8(1):1-14

45. Hervey SL, Purves HR, Guller U, Toth AP, Vail TP, Pietrobon R (2003) Provider volume of total knee arthroplasties and patient outcomes in the hcup-nationwide inpatient sample. J Bone Jt Surg Am 85a(9):1775-1783

46. Higgins JP, Thompson SG (2002) Quantifying heterogeneity in a meta-analysis. Stat Med 21(11):1539-1558

47. Husted H, Hansen HC, Holm G, Bach-Dal C, Rud K, Andersen KL et al (2006) Length of stay in total hip and knee arthroplasty 
in Danmark I: Volume, morbidity, mortality and resource utilization. A national survey in orthopaedic departments in Denmark. Ugeskr Laeger 168(22):2139-2143

48. Inacio MCS, Paxton EW, Graves SE, Namba RS, Nemes S (2017) Projected increase in total knee arthroplasty in the United States - an alternative projection model. Osteoarthr Cartil 25(11):1797-1803

49. Institut für Qualität und Wirtschaftlichkeit im Gesundheitswesen (IQWiG) (2005) Entwicklung und anwendung von modellen zur berechnung von schwellenwerten bei mindestmengen für die knie-totalendoprothese. Abschlussbericht b05/01a. Stiftung für Qualität und Wirtschaftlichkeit im Gesundheitswesen, rechtsfähige Stiftung des bürgerlichen Rechts, Cologne (Germany). https://www.iqwig.de/download/b05-01a_abschlussbericht_ entwicklung_und_anwendung_von_modellen_zur_berechnung von_schwellenwerten_bei_mindestmengen_fuer_die_knie-total endoprothese.pdf?rev=117386. Accessed 17 Feb 2021

50. Jeschke E, Citak M, Gunster C, Matthias Halder A, Heller KD, Malzahn J et al (2017) Are TKAs performed in highvolume hospitals less likely to undergo revision than TKAs performed in low-volume hospitals? Clin Orthop Relat Res 475(11):2669-2674

51. Judge A, Chard J, Learmonth I, Dieppe P (2006) The effects of surgical volumes and training centre status on outcomes following total joint replacement: analysis of the hospital episode statistics for England. J Public Health (Oxf) 28(2):116-124

52. Katz JN, Barrett J, Mahomed NN, Baron JA, Wright RJ, Losina E (2004) Association between hospital and surgeon procedure volume and the outcomes of total knee replacement. J Bone Jt Surg Am 86a(9):1909-1916

53. Katz JN, Bierbaum BE, Losina E (2008) Case mix and outcomes of total knee replacement in orthopaedic specialty hospitals. Med Care 46(5):476-480

54. Kreder HJ, Grosso P, Williams JI, Jaglal S, Axcell T, Wal EK et al (2003) Provider volume and other predictors of outcome after total knee arthroplasty: a population study in Ontario. Can J Surg 46(1):15-22

55. Kugler CM, De Santis KK, Rombey T, Goossen K, Breuing J, Könsgen N et al (2021) Perspective of potential patients on the hospital volume-outcome relationship and the minimum volume threshold for total knee arthroplasty: a qualitative focus group and interview study. BMC Health Serv Res 21(1):1-17. https:// doi.org/10.1186/s12913-021-06641-8

56. Lau RL, Perruccio AV, Gandhi R, Mahomed NN (2012) The role of surgeon volume on patient outcome in total knee arthroplasty: a systematic review of the literature. BMC Musculoskelet Disord 13(1):250

57. Lee QJ, Mak WP, Wong YC (2016) Mortality following primary total knee replacement in public hospitals in Hong Kong. Hong Kong Med J 22(3):237-241

58. Lenguerrand E, Whitehouse MR, Beswick AD, Kunutsor SK, Foguet P, Porter M et al (2019) Risk factors associated with revision for prosthetic joint infection following knee replacement: an observational cohort study from England and Wales. Lancet Infect Dis 19(6):589-600

59. Luft HS, Hunt SS, Maerki SC (1987) The volume-outcome relationship: practice-makes-perfect or selective-referral patterns? Health Serv Res 22(2):157-182

60. Maman SR, Andreae MH, Gaber-Baylis LK, Turnbull ZA, White RS (2019) Medicaid insurance status predicts postoperative mortality after total knee arthroplasty in state inpatient databases. J Comp Eff Res 8(14):1213-1228

61. Manley M, Ong K, Lau E, Kurtz SM (2009) Total knee arthroplasty survivorship in the United States Medicare population: Effect of hospital and surgeon procedure volume. J Arthroplast 24(7):1061-1067
62. Marlow NE, Barraclough B, Collier NA, Dickinson IC, Fawcett J, Graham JC et al (2010) Centralization and the relationship between volume and outcome in knee arthroplasty procedures. ANZ J Surg 80(4):234-241

63. McGowan J, Sampson M, Salzwedel DM, Cogo E, Foerster V, Lefebvre C (2016) Press peer review of electronic search strategies: 2015 guideline statement. J Clin Epidemiol 75:40-46

64. McMaster University (2020) Gradepro gdt: Gradepro guideline development tool. Evidence Prime Inc, Hamilton. https://grade pro.org/. Accessed 14 Sept 2020

65. Meehan JP, Danielsen B, Kim SH, Jamali AA, White RH (2014) Younger age is associated with a higher risk of early periprosthetic joint infection and aseptic mechanical failure after total knee arthroplasty. J Bone Jt Surg Am 96A(7):529-535

66. Mesman R, Westert GP, Berden BJ, Faber MJ (2015) Why do high-volume hospitals achieve better outcomes? A systematic review about intermediate factors in volume-outcome relationships. Health Policy 119(8):1055-1067

67. Meyer E, Weitzel-Kage D, Sohr D, Gastmeier P (2011) Impact of department volume on surgical site infections following arthroscopy, knee replacement or hip replacement. BMJ Qual Saf 20(12):1069-1074

68. Mitsuyasu S, Hagihara A, Horiguchi H, Nobutomo K (2006) Relationship between total arthroplasty case volume and patient outcome in an acute care payment system in Japan. J Arthroplasty 21(5):656-663

69. Morche J, Mathes T, Pieper D (2016) Relationship between surgeon volume and outcomes: a systematic review of systematic reviews. Syst Rev 5(1):204

70. Morche J, Renner D, Pietsch B, Kaiser L, Brönneke J, Gruber S et al (2018) International comparison of minimum volume standards for hospitals. Health Policy 122(11):1165-1176

71. Muilwijk J, van den Hof S, Wille JC (2007) Associations between surgical site infection risk and hospital operation volume and surgeon operation volume among hospitals in the Dutch nosocomial infection surveillance network. Infect Control Hosp Epidemiol 28(5):557-563

72. Murad MH, Mustafa RA, Schünemann HJ, Sultan S, Santesso N (2017) Rating the certainty in evidence in the absence of a single estimate of effect. Evid Based Med 22(3):85-87

73. Namba RS, Cafri G, Khatod M, Inacio MC, Brox TW, Paxton EW (2013) Risk factors for total knee arthroplasty aseptic revision. J Arthroplast 28(8 Suppl):122-127

74. Namba RS, Inacio MC, Paxton EW (2013) Risk factors associated with deep surgical site infections after primary total knee arthroplasty: an analysis of 56,216 knees. J Bone Jt Surg Am 95(9):775-782

75. Nimptsch U, Mansky T (2017) Hospital volume and mortality for 25 types of inpatient treatment in German hospitals: Observational study using complete national data from 2009 to 2014. BMJ Open 7(9):19

76. Nimptsch U, Peschke D, Mansky T (2017) Minimum caseload requirements and in-hospital mortality: observational study using nationwide hospital discharge data from 2006 to 2013. Gesundheitswesen 79(10):823-834

77. Norton EC, Garfinkel SA, McQuay LJ, Heck DA, Wright JG, Dittus R et al (1998) The effect of hospital volume on the in-hospital complication rate in knee replacement patients. Health Serv Res 33(5 Pt 1):1191-1210

78. Ohmann C, Verde PE, Blum K, Fischer B, de Cruppe W, Geraedts M (2010) Two short-term outcomes after instituting a national regulation regarding minimum procedural volumes for total knee replacement. J Bone Jt Surg Am 92(3):629-638

79. Ong KL, Lau E, Manley M, Kurtz SM (2008) Effect of procedure duration on total hip arthroplasty and total knee arthroplasty 
survivorship in the United States Medicare population. J Arthroplast 23(6):127-132

80. Page MJ, McKenzie JE, Bossuyt PM, Boutron I, Hoffmann TC, Mulrow CD et al (2021) The PRISMA 2020 statement: an updated guideline for reporting systematic reviews. Syst Rev 10(1):89

81. Pamilo KJ, Peltola M, Paloneva J, Makela K, Hakkinen U, Remes V (2015) Hospital volume affects outcome after total knee arthroplasty. Acta Orthop 86(1):41-47

82. Pamilo KJ, Torkki P, Peltola M, Pesola M, Remes V, Paloneva J (2018) Fast-tracking for total knee replacement reduces use of institutional care without compromising quality. A register-based analysis of 4 hospitals and 4256 replacements. Acta Orthop 89(2):184-189

83. Paterson JM, Williams JI, Kreder HJ, Mahomed NN, Gunraj N, Wang X et al (2010) Provider volumes and early outcomes of primary total joint replacement in Ontario. Can J Surg 53(3):175-183

84. Pieper D, Mathes T, Neugebauer E, Eikermann M (2013) State of evidence on the relationship between high-volume hospitals and outcomes in surgery: a systematic review of systematic reviews. J Am Coll Surg 216(5):1015-1025.e1018

85. Piuzzi NS, Strnad GJ, Ali Sakr Esa W, Barsoum WK, Bloomfield MR, Brooks PJ et al (2019) The main predictors of length of stay after total knee arthroplasty: patient-related or procedure-related risk factors. J Bone Jt Surg Am 101(12):1093-1101

86. Polonski A, Izbicki JR, Uzunoglu FG (2019) Centralization of pancreatic surgery in Europe. J Gastrointest Surg 23(10):2081-2092

87. Price AJ, Alvand A, Troelsen A, Katz JN, Hooper G, Gray A et al (2018) Knee replacement. Lancet 392(10158):1672-1682

88. Ravi B, Croxford R, Hollands S, Paterson JM, Bogoch E, Kreder $\mathrm{H}$ et al (2014) Increased risk of complications following total joint arthroplasty in patients with rheumatoid arthritis. Arthritis Rheumatol 66(2):254-263

89. Rombey T, Goossen K, Breuing J, Mathes T, Hess S, Burchard R, et al (2019) Hospital volume-outcome relationship in total knee arthroplasty: a systematic review and non-linear dose-response meta-analysis. Prospero 2019 crd42019131209. National Institute for Health Research. International prospective register of systematic reviews, York, UK. https://www.crd.york.ac.uk/prosp ero/display_record.php?ID=CRD42019131209. Accessed 19 Nov 2020

90. Rombey T, Goossen K, Breuing J, Mathes T, Hess S, Burchard R et al (2020) Hospital volume-outcome relationship in total knee arthroplasty: protocol for a systematic review and non-linear dose-response meta-analysis. Syst Rev 9(1):38. https://doi.org/ 10.1186/s13643-020-01295-9

91. Santesso N, Glenton C, Dahm P, Garner P, Akl EA, Alper B et al (2020) Grade guidelines 26: informative statements to communicate the findings of systematic reviews of interventions. J Clin Epidemiol 119:126-135

92. Schaal T, Schoenfelder T, Klewer J, Kugler J (2017) Effects of perceptions of care, medical advice, and hospital quality on patient satisfaction after primary total knee replacement: a crosssectional study. PLoS ONE 12(6):e0178591

93. Schrader P, Grouven U, Bender R (2007) Is it possible to calculate minimum provider volumes for total knee replacement using routine data? Results of a threshold value analysis of German quality assurance data for inpatient treatment. Der Orthopade 36(6):570-576

94. Schulze Raestrup U, Smektala R (2006) Are there relevant minimum procedure volumes in trauma and orthopedic surgery? Zentralbl Chir 131(6):483-492

95. Schünemann HJ, Cuello C, Akl EA, Mustafa RA, Meerpohl JJ, Thayer K et al (2019) Grade guidelines: 18. How Robins-I and other tools to assess risk of bias in nonrandomized studies should be used to rate the certainty of a body of evidence. J Clin Epidemiol 111:105-114

96. Shervin N, Rubash HE, Katz JN (2007) Orthopaedic procedure volume and patient outcomes: a systematic literature review. Clin Orthop Relat Res 457:35-41

97. Shin CH, Chang CB, Cho SH, Jeong JH, Kang SB (2015) Factors associated with the incidence of revision total knee arthroplasty in Korea between 2007 and 2012: an analysis of the National Claim Registry. BMC Musculoskelet Disord 16(1):1-8

98. Singh JA, Kwoh CK, Boudreau RM, Lee GC, Ibrahim SA (2011) Hospital volume and surgical outcomes after elective hip/knee arthroplasty: a risk-adjusted analysis of a large regional database. Arthritis Rheum 63(8):2531-2539

99. Skou ST, Roos EM, Laursen MB, Rathleff MS, Arendt-Nielsen L, Simonsen O et al (2015) A randomized, controlled trial of total knee replacement. N Engl J Med 373(17):1597-1606

100. Solomon DH, Chibnik LB, Losina E, Huang J, Fossel AH, Husni E et al (2006) Development of a preliminary index that predicts adverse events after total knee replacement. Arthritis Rheum 54(5):1536-1542

101. Song KH, Kim ES, Kim YK, Jin HY, Jeong SY, Kwak YG et al (2012) Differences in the risk factors for surgical site infection between total hip arthroplasty and total knee arthroplasty in the Korean Nosocomial Infections Surveillance System (Konis). Infect Control Hosp Epidemiol 33(11):1086-1093

102. SooHoo NF, Lieberman JR, Ko CY, Zingmond DS (2006) Factors predicting complication rates following total knee replacement. J Bone Jt Surg Am 88(3):480-485

103. SooHoo NF, Zingmond DS, Lieberman JR, Ko CY (2006) Optimal timeframe for reporting short-term complication rates after total knee arthroplasty. J Arthroplast 21(5):705-711

104. Soohoo NF, Zingmond DS, Lieberman JR, Ko CY (2006) Primary total knee arthroplasty in California 1991-2001: Does hospital volume affect outcomes? J Arthroplast 21(2):199-205

105. Steinbrück A, Grimberg A, Melsheimer O, Jansson V (2020) Influence of institutional experience on results in hip and knee total arthroplasty: an analysis from the German Arthroplasty Registry (EPRD). Der Orthopade 49(9):808-814

106. Stengel D (2012) Auswirkungen der regelungen über mindestmengen. Unfallchirurg 115(9):840-843

107. Stengel D, Ekkernkamp A, Dettori J, Hanson B, Sturmer KM, Siebert H (2004) A rapid review of the minimum quality problems using total knee arthroplasty as an example. Where do the magical threshold values come from? Unfallchirurg 107(10):967-988

108. Sterne JAC, Hernán MA, Reeves BC, Savović J, Berkman ND, Viswanathan M et al (2016) Robins-i: a tool for assessing risk of bias in non-randomised studies of interventions. BMJ 355:i4919

109. Sterne JAC, Sutton AJ, Ioannidis JPA, Terrin N, Jones DR, Lau $\mathrm{J}$ et al (2011) Recommendations for examining and interpreting funnel plot asymmetry in meta-analyses of randomised controlled trials. BMJ 343:d4002

110. Street A, Gutacker N, Bojke C, Devlin N, Daidone S (2014) Health services and delivery research. In: Variations in outcome and costs among NHS providers for common surgical procedures: Econometric analyses of routinely collected data. NIHR Journals Library. Health Services and Delivery Research, Southampton https://doi.org/10.3310/hsdr02010

111. Styron JF, Koroukian SM, Klika AK, Barsoum WK (2011) Patient vs provider characteristics impacting hospital lengths of stay after total knee or hip arthroplasty. J Arthroplast 26(8):1418-1426

112. Taylor HD, Dennis DA, Crane HS (1997) Relationship between mortality rates and hospital patient volume for Medicare patients 
undergoing major orthopaedic surgery of the hip, knee, spine, and femur. J Arthroplast 12(3):235-242

113. The GRADE Working Group, Schünemann H, Brożek J, Guyatt G, Oxman A (2013) Grade handbook for grading quality of evidence and strength of recommendations. Updated October 2013. McMaster University und Evidence Prime Inc, Hamilton. https://gdt.gradepro.org/app/handbook/handbook.html. Accessed 14 Sept 2020

114. Tsai YS, Kung PT, Ku MC, Wang YH, Tsai WC (2018) Effects of pay for performance on risk incidence of infection and of revision after total knee arthroplasty in type 2 diabetic patients: A nationwide matched cohort study. PLoS ONE 13(11):e0206797

115. Varagunam M, Hutchings A, Black N (2015) Relationship between patient-reported outcomes of elective surgery and hospital and consultant volume. Med Care 53(4):310-316

116. Viechtbauer W (2017) The metafor package: a meta-analysis package for R. http://www.metafor-project.org/doku.php. Accessed 02 Feb 2017

117. von Elm E, Altman DG, Egger M, Pocock SJ, Gøtzsche PC, Vandenbroucke JP (2007) The strengthening the reporting of observational studies in epidemiology (strobe) statement: guidelines for reporting observational studies. PLoS Med 4(10):e296
118. Wei MH, Lin YL, Shi HY, Chiu HC (2010) Effects of provider patient volume and comorbidity on clinical and economic outcomes for total knee arthroplasty: a population-based study. $\mathbf{J}$ Arthroplast 25(6):906-912.e901

119. Welsh RL, Graham JE, Karmarkar AM, Leland NE, Baillargeon JG, Wild DL et al (2017) Effects of postacute settings on readmission rates and reasons for readmission following total knee arthroplasty. JAMDA 18(4):367-e361

120. Wilson S, Marx RG, Pan TJ, Lyman S (2016) Meaningful thresholds for the volume-outcome relationship in total knee arthroplasty. J Bone Jt Surg Am 98(20):1683-1690

121. Yasunaga H, Tsuchiya K, Matsuyama Y, Ohe K (2009) Analysis of factors affecting operating time, postoperative complications, and length of stay for total knee arthroplasty: nationwide webbased survey. J Orthop Sci 14(1):10-16

122. Yu TH, Chou YY, Tung YC (2019) Should we pay attention to surgeon or hospital volume in total knee arthroplasty? Evidence from a nationwide population-based study. PLoS ONE 14(5):12

Publisher's Note Springer Nature remains neutral with regard to jurisdictional claims in published maps and institutional affiliations. 